\title{
The Relationship Between the Marketing Mix and Share of Category Requirements
}

\author{
C.B. BHATTACHARYA \\ Department of Marketing, Goitueta Business School, Emory University
}

PETER S. FADER

Department of Marketing, Wharton School, SH-DH 1400, University of Pennsylvania, Philadelphia, PA 19104-6371

LEONARD M. LODISH

Department of Marketing, University of Pennsylvania

WAYNE S. DESARBO

Marketing and Statistics Department, University of Michigan

Key words: brand loyalty, marketing mix, share of category requirements, scanner data

\begin{abstract}
A criticism of purchase-based brand loyalty measures is that they are confounded by the marketing mix variables that affect brand choice. This paper investigates the magnitude and direction of the associations for share of category requirements (SCR), defined as each brand's share among the group of households who bought the brand at least once during the time period under consideration. We discuss the theoretical foundations for the relationships between SCR and a set of marketing mix variables (price, promotions, retail distribution) and conduct a latent structure regression analysis of brand-level data to test these relationships. We find that, although the relationship between the marketing mix variables and SCR is statistically significant, in real terms the magnitude of the association is fairly low.
\end{abstract}

\section{Introduction}

The measurement of brand loyalty has been a much-discussed topic in marketing for several decades. Interest in this topic has been aided by the growth of scanner panel data and the concomitant increase in the number and variety of loyalty measures that are derived from the purchasing behavior of households. Several researchers (for example, Lattin, 1990; Little and Anderson, 1994; Ortmeyer, Lattin, and Montgomery, 1991; Russell, 1994; Srinivasan and Kibarian, 1989) have highlighted the shortcomings of loyalty measures that are based solely on purchase histories. The most common criticism is that such measures are impacted by the effects that marketing mix inducements (such as price and promotional activities) may have had on households' brand choices. The spirit of the argument is conveyed by Allenby and Rossi (1991), who comment that "traditional loyalty measures based on purchase incidence alone do not consider the possibility that a household might appear to be very 'loyal' simply because the brand was frequently on sale in the first half of the data" (p. 192). 
From a managerial standpoint, the relationship between the marketing mix and brand loyalty is extremely relevant. If currently used loyalty measures reflect the impact of marketing mix variables, there may be a need to develop purified measures and also to caution managers about interpreting the observed loyalty levels of their brands. If, on the other hand, the impact of marketing mix is only slight, managers should be able to use existing measures with greater confidence. Hence, it is important to conduct an investigation across a large number of brands and product categories to understand whether and how the marketing mix variables are related to a loyalty measure that is used regularly in actual practice.

What do practicing managers and researchers use as a measure of brand loyalty? Since the earliest diary panels were introduced, the notion of "share of category requirements" has been the most common loyalty measure used by most major market researchers. Simply stated, share of category requirements (SCR) measures each brand's market share among the group of households that bought the brand at least once during the time period under consideration. The largest vendors of syndicated panel data-Information Resources, Inc. and Nielsen Marketing Research-regularly report SCR estimates for most of the brands covered in their extensive databases. Although it may be called by different names, ${ }^{1}$ SCR is typically the only measure of brand loyalty that most marketing managers see on a regular basis (Hume, 1992). Furthermore, there is little doubt that, because of the difficulties of changing production systems and reeducating large user bases, SCR will continue to be the primary loyalty measure used in practice for the foreseeable future.

Our objective in this paper, therefore, is to conduct an investigation of both the magnitude and direction in which SCR relates to three managerially controllable variables (price, promotion, and distribution). Our goal is not to test whether or not loyalty levels have actually been eroding over time (see Johnson, 1984, 1991) but to examine brand-level data across a large number of categories and brands in order to comprehend the degree of association between SCR and different marketing activities.

We proceed as follows. We first introduce SCR very briefly. ${ }^{2}$ Next we investigate how SCR may be related to a standard set of marketing mix variables: we review the foundations for these different relationships and then examine them empirically using a latent structure regression model and an extensive cross-category database (IRI's Marketing Factbook). Finally, we examine the parameter estimates from this regression model and conduct additional analyses to uncover the extent and manner in which SCR is related to the marketing mix and discuss some implications of our results.

\section{Share of Category Requirements}

SCR is generally reported strictly at an aggregate level, but it can be expressed as the weighted average of a collection of household-level measures, where each is simply the choice share of each brand:

$$
\operatorname{SCR}_{h i}(T)=\frac{\Sigma_{t \in T} q_{h i}(t)}{\Sigma_{j} \Sigma_{t \in T} q_{h j}(t)}
$$


where

$S C R_{h i}(T)=$ household $h$ 's share of category requirements for brand $i$ during time period $T$ (which often refers to a month, a quarter, or a year),

$q_{h i}(t)=$ quantity of brand $i$ purchased by household $h$ on purchase occasion $t$ (where $t$ is an index of all purchase occasions during time period $T$ ), and $j=$ index for all brands in the category.

Several academic researchers have used household-level loyalty measures similar to equation (1), often referring to them by names other than "sharc of catcgory requirements." In some cases, researchers ignore the purchase quantity, and replace $q_{h i}(t)$ with a simple $0 / 1$ variable indicating whether or not brand $i$ was purchased by household $h$ at time $t$. A well-known application of this type of loyalty variable is found in a paper by Krishnamurthi and Raj (1988); it has also been used by other researchers, including Lattin and Bucklin (1989) and Russell and Kamakura (1994).

To compute the market-level SCR statistic, the household-level choice share measure in equation (1) is aggregated across households by weighting each household by its total purchase quantity:

$$
S C R_{i}(T)=\frac{\Sigma_{h} S C R_{h i}(T) Q_{h}(T)}{\Sigma_{h \in i} Q_{h}(T)},
$$

where

$S C R_{i}(T)=$ aggregate share of category requirements of brand $i$ during time period $T$,

$S C R_{h i}(T)=$ household-level share of category requirements, defined in (1), $Q_{h}(T)=\Sigma_{t \in T} \Sigma_{j} q_{h j}(t)=$ total quantity purchased by household $h$ during time period $T$.

The $h \in i$ delimiter in the denominator denotes that the sum is only taken across households that have bought brand $i$ at least once in the dataset under consideration. Note that higher levels of SCR may not necessarily connote higher levels of market share or profitability: to take an extreme example, if a brand has one buyer who buys it all the time, the SCR for this brand will be 1.0, but the firm will probably not prosper. Our interest is not in appraising the "goodness" of SCR but rather in understanding the relationship it bears to the marketing mix environment. We discuss these issues in greater detail in the following section.

\section{Expected Associations Between Marketing Mix Variables and SCR}

We elaborate on the various ways in which the SCR estimates may be related to four marketing variables: average base price, consumer use of retail promotions, depth of promotional discounts, and breadth of retail availability. We restrict our discussion to the specific definitions of these variables provided in Information Resources' Marketing Factbook and InfoScan Supermarket Review, since we use these measures subsequently in our empirical tests. 


\subsection{Average Price}

Average price is defined as the average base (unpromoted) price for each brand relative to the other brands in the product category. Given that units of measurement differ across categories, we do not measure it as dollars per item or unit volume but rather as dollars spent per transaction in the category, adjusted for any price promotions. There are reasonable arguments supporting both a positive and a negative relationship between SCR and average price.

On the positive side, price is often used as a cue for brand quality (Etgar and Malhotra, 1981). Higher-priced brands are often perceived by consumers as offering superior quality (see Gabor and Granger, 1966; Monroe, 1973). Following this logic, consumers who purchase high-priced brands do so because they value the benefits that each brand has to offer and are therefore reluctant to switch to other brands in the category.

On the other hand, consider what happens when a high-priced brand indulges in temporary price reductions. It is well-documented that price-sensitive consumers are willing to purchase the more expensive (presumably higher quality) brand when it falls within their latitude of price acceptance (Allenby and Rossi, 1991; Blattberg and Wisniewski, 1989). However, since these consumers do not buy the high-priced brand under normal circumstances, its SCR level will be affected adversely: it will suddenly have a larger base of buyers who rarely buy the brand. Given that almost all brands use some amount of temporary price reductions, this line of reasoning suggests that price may be negatively related to SCR. Thus, it is difficult to say whether one of these directional effects will outweigh the other.

\subsection{Consumer Use of Retail Promotions}

This variable measures each brand's percent of total sales purchased by consumers when it is promoted by the retailer, compared to the other brands in the category. Retail promotions include newspaper features, in-store displays, short-term price cuts, and store coupons. There are two ways in which retail promotions can affect SCR. First, these promotions may affect the repeat purchase behavior of existing users of the brand; second, promotions may temporarily attract new customers and thereby increase the total number of triers. In both cases, we intuitively expect to see a negative relationship between the extent to which a brand sells on promotion and its SCR level (see Kahn and Louie, 1990).

In contrast, some studies suggest that these negative effects may be exaggerated or even nonexistent. For example, Neslin and Shoemaker (1989) suggest that the negative promotion effects described by Dodson, Tybout, and Sternthal (1978) may simply be an artifact from aggregating across panelists with different purchase rates. Moreover, several recent papers have shown no negative promotional effects on brand loyalty (see Davis, Inman, and McAlister, 1992; Ehrenberg, Hammond, and Goodhardt, 1994; Johnson, 1984, 1991). Thus, while intuition seems to suggest a negative relationship between the frequency of consumer purchases on deal and SCR, we cannot be sure whether the relationship is strongly negative or whether it may actually be indistinguishable from zero. 


\subsection{Retail Price Promotion Depth}

This variable represents how deeply a brand cuts price when on deal, compared to the average depth of price cut of all the brands in the category. Numerous papers (see Kalwani et al., 1990; Lattin and Bucklin, 1989; Winer, 1986) have proposed that customers form expected or reference prices for brands on the basis of the prices paid or observed during previous purchase occasions. Thus, if a brand indulges in deeper price cuts, it is likely that consumers will have a lower reference price for that brand, which may have a corresponding negative effect on its repeat purchase during nonpromoted times. Similar results are predicted by some of the other psychological theories mentioned in the previous section, such as self-perception theory. There is no evidence or logic that suggests anything but a negative relationship in this case.

\subsection{Retail Availability}

Our measure of distribution is percent all commodity volume (PACV), defined as the percent of total grocery volume sold by stores that stock the brand of interest. All else being equal, we expect to see a positive relationship between PACV and SCR; this is consistent with empirical results dating back to Farley (1964) and echoed in more recent papers such as Fader and Schmittlein (1993) and Farris, Olver, and de Kluyver (1989).

Farris, Olver, and de Kluyver (1989) demonstrate that a brand's market share is a convex function of its retail distribution, increasing at an increasing rate up to 100 percent distribution. Several explanations are offered for this relationship, which may also exist for a sharebased measure of brand loyalty such as SCR. First, widely distributed brands will rarely lose potential sales due to unavailability; loyal buyers will seldom be forced to compromise their preferences at the store shelf. Second, small stores will tend to disproportionately favor popular brands, since retailers recognize that they risk losing business if they fail to stock these brands. Similarly, Fader and Schmittlein (1993) show that observed SCR estimates are regularly inflated for high-share (presumably well-distributed) brands.

In line with the above arguments, we expect distribution to be positively related to brand loyalty (that is, SCR). It is important to note, however, that this logic may not apply to regionally distributed brands. These brands have lower distribution levels (based on our definition) compared to national brands, but because of their ability to cater to regionspecific tastes (and possible high distribution levels in their limited areas), their SCR levels may be comparable to, if not higher than, those of nationally distributed brands.

\subsection{Summary}

Table 1 provides a summary of the variables of interest, the operational measures, and the hypothesized relationships with SCR. Observe that the theory is mixed in terms of predicting the direction of the relationship between two of the four variables and SCR; this further underscores the need for an empirical investigation to assess the extent to which SCR is associated with the marketing mix. We standardize each variable (including SCR) across 
Table 1. Expected impact of marketing mix variables on SCR.

\begin{tabular}{lll}
\hline \multicolumn{1}{c}{ Variable } & \multicolumn{1}{c}{ Operational Measure } & Expected Signs \\
\hline Average price & $\begin{array}{l}\text { Average base price for each brand, relative to other } \\
\text { brands in the category (PRICE) }\end{array}$ & $+/-$ \\
Consumers' use of retail & $\begin{array}{l}\text { Percent of brand's total sales on retail promotion } \\
\text { (newspaper features, in-store displays, price cuts, } \\
\text { promotions }\end{array}$ & $\begin{array}{l}\text { and store coupons) (PROMO) } \\
\text { Retail price promotion depth }\end{array}$ \\
& $\begin{array}{l}\text { Percent of price cut on deal, relative to average } \\
\text { depth of price cuts by all brands in the category } \\
\text { (PCUT) }\end{array}$ \\
Retail availability & $\begin{array}{l}\text { Percent all commodity volume: percent of total } \\
\text { grocery volume sold by stores that stock the brand } \\
\text { of interest (PACV) }\end{array}$ \\
\hline
\end{tabular}

the eligible brands within each category: for each variable we subtract the category mean and divide by the category standard deviation. Standardization makes the variables comparable across categories and facilitates the estimation of a cross-sectional model.

\section{The Data}

Most of the data for our empirical analysis are taken from the IRI s 1988 Marketing Factbook, which is a compilation of household-level purchasing data from a panel of 35,000 households in twenty-seven different metropolitan markets. The data are projected to provide an aggregate representation of nationwide grocery purchasing. The Marketing Factbook contains purchase information on 348 categories and 7,633 brands during the period January 1988 to December 1988 for four of the variables discussed above: SCR, average price, consumer use of retail promotions, and depth of retail price promotions. To obtain information on percent ACV, we use another IRI publication, the InfoScan Supermarket Review, which provides distribution information on 3,878 brands sold through grocery stores. Unfortunately, there is not a perfect correspondence for brands and categories between the Factbook and InfoScan. As a result, some nonoverlapping brands and categories were eliminated from the analysis. However, many of these eliminated brands or categories are relatively small: in Section 4.2 we describe several selection criteria that would have screened out many of these entities anyway.

\subsection{Defining Categories and Brands}

The Marketing Factbook classifies brands into categories and further classifies certain categories into subcategories. For example, the "disposable food storage bag" category combines together a variety of subcategories, from freezer bags to microwave bags to sandwich bags. Similarly, "ready-to-drink fruit juices" includes subcategories ranging from apple juice to prune juice to grapefruit juice. We believe that the subcategory level is the most 
appropriate level of aggregation for the analysis to follow: marketers likely formulate their programs in accordance with the actions of other brands within these subcategories, and consumers may be more prone to switch among brands within a particular subcategory rather than the full category. Therefore, for the subdivided categories in our analysis, we implicitly treat IRI's subcategory definitions as categories.

Our model is estimated at the brand level. A brand, in this study, is an aggregation of different package sizes and product forms that share the same brand namc. Wc abidc strictly by the brand definitions created by IRI; for example, Coke, Coke Classic, and Diet Coke are distinct brands, but the caffeine-free versions of each are combined together with the regular (caffeinated) versions.

\subsection{Screening Criteria}

To ensure the validity of our results we applied four screening criteria to eliminate inappropriate categories and brands:

- Only branded products: Any Factbook or InfoScan report that mentions private labels or generics is not referring to any one brand in particular but merely communicates aggregate totals across these different store brands. Therefore, all private labels and generics were eliminated from the analysis.

- Number of brands in the category: As measured by SCR, loyalty is a competitive phenomenon. We only retained categories that had at least three eligible brands.

- Number of purchases per household: The SCR measure is highly volatile when reported for a small number of purchase occasions. We therefore eliminated categories in which the average number of purchases per buyer was under three per year.

- Share of overall category volume: Finally, we retained only those categories for which the total market share of eligible brands exceeded 50 percent. This was done to ensure that the brands included in the analysis represent their respective categories fairly well.

As a result of these screens, 1,379 brands belonging to 120 categories were included for analysis. This set accounts for over 40 percent of the total volume of purchases reported in the Factbook. Table 2 presents some key summary statistics of our sample as compared to the population of items in the Factbook.

With the exception of SCR and PROMO, these statistics do not differ greatly from the selected sample to the overall population of brands. The difference in SCR may be due to the fact that we eliminated categories with few competing brands, which would generally have unusually high SCR levels. The remaining differences seem to be an outcome of our effort to eliminate private labels and generics. It makes sense that these items would have lower prices, less frequent promotions, and smaller price cuts than many national brands. Finally, Table 3 contains the correlation matrix for the variables included in the analysis to follow. 
Table 2. Summary statistics for population and sample.

\begin{tabular}{|c|c|c|c|c|}
\hline \multirow[b]{2}{*}{ Variable } & \multicolumn{2}{|c|}{ Population $(\mathrm{N}=7633)$} & \multicolumn{2}{|c|}{ Sample $(\mathrm{N}=1379)$} \\
\hline & Mean & Standard Deviation & Mean & Standard Deviation \\
\hline Market share (\%) & 3.83 & 9.00 & 3.23 & 5.60 \\
\hline SCR $(\%)$ & 25.12 & 20.43 & 18.53 & 12.17 \\
\hline PRICE $(\$)^{\mathrm{a}}$ & 1.81 & 1.09 & 2.00 & 1.15 \\
\hline $\operatorname{PACV}(\%)^{\mathrm{b}}$ & 56.82 & 32.94 & 59.90 & 34.13 \\
\hline PROMO (\%) & 28.96 & 20.57 & 35.78 & 19.14 \\
\hline PCUT (\%) & 23.88 & 10.40 & 26.03 & 8.34 \\
\hline
\end{tabular}

${ }^{a}$ To ensure comparability across categories, we report price here as average dollars spent per transaction in each category.

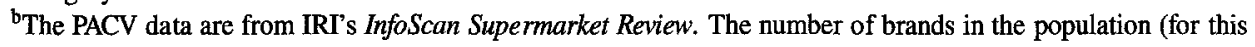
variable only) is 3,878 .

Table 3. Correlation matrix $(N=1379)$.

\begin{tabular}{lrrrrr}
\hline & \multicolumn{1}{c}{ SCR } & PRICE & PROMO & PCUT & PACV \\
\hline SCR & 1.000 & & & & \\
PRICF & -0.271 & 1.000 & & & \\
PROMO & 0.051 & -0.389 & 1.000 & & \\
PCUT & -0.119 & -0.146 & 0.330 & 1.000 & \\
PACV & 0.135 & 0.214 & -0.065 & 0.100 & 1.000 \\
\hline
\end{tabular}

\section{Model Estimation and Results}

To simultaneously test the hypotheses discussed above, we estimate the following multipleregression model:

$$
S C R_{i}=\alpha+\beta_{1} \text { PRICE }_{i}+\beta_{2} \text { PROMO }_{i}+\beta_{3} P C U T_{i}+\beta_{4} P A C V_{i}+\epsilon_{i},
$$

where $i$ refers to each brand in the sample, the variables are as defined in Table 1 , the $\beta$ s are parameters to be estimated, and $\epsilon_{i}$ is a random error term. We recognize that this model does not capture all of the variables that may affect each brand's SCR; factors such as category and consumer characteristics, advertising, and a variety of possible interaction terms may also play a role in explaining SCR differences across brands. Nevertheless, these are the only suitable measures available from the syndicated sources used to construct our database. Thus, these measures reflect the types of data that managers are most likely to encounter on a regular basis. We have no reason to believe that the omission of certain variables changes any of the principal results we discuss later on.

The first column of Table 4 provides the results of this regression analysis. Although the regression model is significant, its $R^{2}$ is rather low $(0.148)$. While this model may offer some initial insight into the overall relationship between SCR and the independent 
Table 4. Latent structure regression solution.

\begin{tabular}{|c|c|c|c|c|}
\hline \multirow{2}{*}{$\begin{array}{c}\text { Independent } \\
\text { Variable }\end{array}$} & \multirow[b]{2}{*}{$K=1^{\mathrm{a}}$} & \multicolumn{3}{|c|}{$K=3$} \\
\hline & & Cluster 1 & Cluster 2 & Cluster 3 \\
\hline Intercept & -.0053 & $1.53^{\mathrm{b}}$ & $0.173^{b}$ & $-0.638^{b}$ \\
\hline PRICE & $-0.3488^{b}$ & $-0.269^{b}$ & $-0.523^{b}$ & $-0.162^{b}$ \\
\hline PROMO & -0.0077 & -0.081 & 0.019 & -0.038 \\
\hline PCUT & $-0.1899^{b}$ & $-0.185^{b}$ & $-0.237^{b}$ & $-0.080^{b}$ \\
\hline PACV & $0.2264^{b}$ & 0.100 & $0.288^{b}$ & $0.131^{b}$ \\
\hline$\lambda_{k}$ & - & 0.12 & 0.46 & 0.42 \\
\hline$\theta_{k}^{2}$ & - & 0.58 & 0.66 & 0.51 \\
\hline
\end{tabular}

${ }^{a}$ This model was run as an OLS regression model; hence the $\lambda_{k}$ and $\theta_{k}^{2}$ values are not reported. $\mathrm{b}_{p}<.01$.

variables, it cannot accommodate brand by brand (or category by category) differences in the relationships examined here. More realistically, it is likely that the full set of brands is characterized by a wide variety of regression coefficients, which may differ both in magnitude and direction. Our hypotheses and conceptual discussion in Section 3 clearly suggest such potential differences.

In order to accommodate potential heterogeneity among this sample of brands, we utilize a latent structure regression framework (see DeSarbo and Cron, 1988; DeSarbo and Wedel, 1995). This methodology, also known as clusterwise regression, permits the estimation of separate regression coefficients for one or more (unknown) clusters of brands. For a desired configuration consisting of $K$ clusters, this model simultaneously estimates $K$ sets of regression coefficients as well as $K$ mixing proportions $\left(\lambda_{k}\right)$ that indicate the relative sizes of each cluster, and $K$ variance terms $\left(\theta_{k}^{2}\right)$ that convey the squared standard error associated with each cluster's regression equation. (When $K=1$, the model is identical to the OLS regression mentioned earlier). DeSarbo and Cron (1988) provide an iterative $\mathrm{E}-\mathrm{M}$ framework that renders estimates for these parameters; we refer the reader to that paper for further details. DeSarbo and Cron (1988) also demonstrate how the model simultaneously determines $\hat{P}_{i k}$, defined as the posterior probability that brand $i$ is a member of the $k$ th cluster or segment, conditioned on the parameter estimates described above. We assign each brand to the cluster that yields the highest value of $\hat{P}_{i k}$.

\subsection{Empirical Results}

The DeSarbo and Cron (1988) procedure was applied to this dataset for $K=1$ to 5 clusters. Table 5 presents the associated goodness-of-fit statistics associated with this methodology. In trying to select the most suitable value of $K$, we rely on two popular criteria, AIC and CAIC (see, for example, Ramaswamy et al., 1993). The $K=3$ solution is best, since it offers the minimum values for both AIC and CAIC. Therefore, we select the three-segment solution. This shows that brands are heterogeneous with regard to the association between the marketing mix variables and SCR and supports the use of a latent structure model. 
Table 5. Latent structure regression results.

\begin{tabular}{ccrcc}
\hline$K$ & $\ln L_{k}$ & $d f_{k}$ & \multicolumn{1}{c}{$A I C_{k}$} & $C A I C_{k}$ \\
\hline 1 & $-1,836.54$ & 6 & $3,691.1$ & $3,722.5$ \\
2 & $-1,792.36$ & 13 & $3,623.7$ & $3,691.7$ \\
3 & $-1,758.48$ & 20 & $3,576.9^{\mathrm{a}}$ & $3,681.5^{\mathrm{a}}$ \\
4 & $-1,748.87$ & 27 & $3,578.7$ & $3,719.9$ \\
5 & $-1,741.84$ & 34 & $3,585.7$ & $3,763.5$ \\
\hline
\end{tabular}

${ }^{a}$ Denotes minimum AIC (CAIC) values.

Columns two through four of Table 4 presents the estimated values of $\lambda_{k}, \beta_{j k}$, and $\theta_{k}^{2}$ for this $K=3$ solution. Before discussing the results, it is important to note that we are not making any causal inferences; the evidence we have is strictly associational. Overall, most of the coefficients appear to be fairly consistent across the clusters. Perhaps the biggest surprise is the consistently strong negative relationship between PRICE and SCR, meaning that, all else being equal, lower-priced brands have higher SCR levels. This is in line with the asymmetric switching argument mentioned earlier: consumers who normally purchase low-priced brands will occasionally switch to a high-priced brand (thereby pulling down its SCR level), but not vice-versa.

Consumer use of retail promotion appears to be unrelated to SCR in all three segments. Perhaps the conflicting arguments discussed earlier simply cancel each other out. This negligible relationship may be a result of the high levels of promotion use shown in Table 2 . Frequent dealing may encourage consumers to anticipate promotion timing and thus alter their purchase timing and quantities accordingly (Krishna, 1991). This in turn may reduce the incentive to switch to other brand's promotions.

In contrast, the negative relationship between the depth of promotional price cuts and SCR is strongly supported. Even if retail promotions in general have little association with SCR, deep price cuts clearly have an effect. It is difficult for a brand to "lock in" loyal buyers through the use of extravagant price promotions.

The relationship between PACV and SCR is positive in all three cases, but the coefficient in cluster 1 is conspicuously insignificant. We believe this is due to the confounding effects of regional brands, as discussed earlier. In any event, the consistently positive pattern seen for PACV decisively underscores the important-but often unappreciated-role that availability plays in brand loyalty.

Finally, given that the variables are all standardized and thus comparable across categories, the intercepts render some information as to each segment's mean value of SCR, adjusted for the marketing mix effects. In other words, the intercepts for the three different clusters convey, in a relative sense, the levels of base loyalty that brands in the different clusters enjoy. Base loyalty refers to each segment's SCR if the marketing mix variables are fixed at the mean levels for each category. Qualitatively, we label clusters 1, 2, and 3 as high-, medium-, and low-loyalty clusters, respectively. These differences in segment-level intercepts, which connote the differences in the underlying loyalty levels of the brands, are clearly the most striking feature seen across the three sets of estimated regression coefficients.

Given that most of the variation across the clusters seems to be attributable to the intercepts, there are two natural follow-up questions: (1) whether the existing latent class model 
Table 6. Performance of competing models.

\begin{tabular}{lcccc}
\hline \multicolumn{1}{c}{ Model } & Ln L & df & AIC & CAIC \\
\hline $\begin{array}{l}\text { Model 1: Heterogeneity in both intercepts and } \\
\text { marketing mix coefficients }\end{array}$ & $-1,758.63$ & 20 & $3,577.25^{\mathrm{a}}$ & $3,681.83^{\mathrm{a}}$ \\
$\begin{array}{l}\text { Model 2: Heterogeneity in intercepts, homogeneity } \\
\text { in marketing mix coefficients }\end{array}$ & $-1,812.42$ & 12 & $3,660.83$ & $3,723.58$ \\
Model 3: Heterogeneous intercepts only & $-1,877.35$ & 8 & $3,778.69$ & $3,820.52$ \\
\hline
\end{tabular}

${ }^{a}$ Denotes minimum value.

performs significantly better than an analogous model with intercept terms only and (2) whether the existing latent class model performs any better compared to a model that allowed heterogeneity in the intercept terms but constrained the marketing mix coefficients to be homogeneous across the clusters. Table 6 gives the results of these analyses.

We observe that the existing latent class model (model 1) outperforms both competing models, as judged by the standard likelihood-based statistics. In practical terms, however, the improvement in performance is modest at best; we observe that in terms of likelihood points, the full model improves on the intercepts-only model by a mere 6.7 percent. Taken together, these results have two contrasting implications. First, we confirm that the relationship between the marketing mix variables and SCR is heterogeneous in nature. Second, and perhaps more important, we observe that, although marketing mix variables are associated with SCR, the overall magnitude of these associations is small.

It is instructive to consider several possible reasons that may explain all or part of this apparent contradiction. We offer three qualitative arguments:

- Household heterogeneity: As discussed in Section 3, one can envision conflicting relationships between SCR and several marketing mix elements, such as price. It could well be the case that, for a particular brand, this link is positive for some households but negative for others. In the aggregate, these counterbalancing forces might cancel out to some extent, thereby limiting the apparent impact of one or more variables. Furthermore, heterogeneity within the household (different tastes or shopping habits by different members of the household) may contribute even further to this reduction in marketing mix impact.

- Cancellation across marketing mix elements: Our latent structure regression results in Table 4, combined with the correlation matrix (Table 3), suggest a subtle but potentially powerful mitigating factor-pairwise cancellation of marketing mix effects. For instance, price and price cut each has a consistently negative (and significant) impact on SCR, according to Table 4 . Yet the two also share a negative pairwise correlation, which might lessen the individual contaminating effects that each variable might have by itself. This same type of pattern is true for several other relevant pairs of marketing mix variables used here (such as price and ACV distribution). Of course, some of the regression coefficients or correlations are rather small in magnitude, but the number of pairs with some degree of cancellation is still quite noteworthy. 
- Limited impact of marketing mix: A less subtle-and potentially more controversialexplanation is that the overall impact of the marketing mix on brand choice may be considerably smaller than most people expect it to be. Consistent evidence for this possibility can be seen in choice models dating back to Guadagni and Little (1983), who produced the first of many logit models in which the variables accounting for cross-sectional heterogeneity were far more influential than any marketing mix element. This observation is also consistent with the work of researchers such as Andrew Ehrenberg, who believe that many marketing mix effects merely show up as short-term blips that do not affect a share-based measure such as SCR to any large extent (see Ehrenberg, Hammond, and Goodhardt, 1994).

Given the type of data we have available to us in this study, it is impossible to formally test or disentangle these various explanations. We leave it as a vital future research direction to better understand the drivers for the surprising phenomenon at the heart of this paper.

\section{Conclusion}

With increasing competition, issues related to brand loyalty are assuming greater importance with marketers. This study has been an effort to obtain answers to some questions of interest in this area. We have concentrated on a single measure of brand loyalty-share of category requirements, which is used by many marketing managers. Although the issue of the relationship between the marketing mix and brand loyalty measures has been much discussed both in the popular press and in the academic literatures, our analysis with regard to SCR shows that the association between the marketing mix and SCR, although significant, is small in magnitude. We also established that the relationship between the marketing mix variables and SCR is heterogeneous in nature.

In coming to the above conclusion, we are not drawing any causal inferences about the relationship between SCR and the marketing mix; our analyses are strictly correlational in nature. Our particular model specification was chosen solely to investigate whether and how this purchase-based loyalty measure is related to a reasonable set of marketing mix variables. We are not suggesting that managers can definitively change a brand's SCR by manipulating the marketing mix in a certain manner. Furthermore, our research focused specifically on the relationship between SCR and the marketing mix, and the finding that the association between the marketing mix and SCR is modest does not in any way imply that SCR is the only measure of brand loyalty or that it is necessarily a flawless measure. A comprehensive assessment of SCR as a measure of brand loyalty is a worthwhile future research endeavor.

An important research direction that emerges from this analysis is a formal investigation of whether the marketing mix variables "contaminate" SCR. In other words, under the assumption that observed SCR is the resultant of underlying preference and the impact of marketing mix on brand choice, we need to investigate whether, despite the incidence of marketing-mix activity, the observed SCR levels continue to be indicative of brands' underlying preference levels. Longitudinal analysis can be conducted in a time-series context, to observe whether changes in the values of marketing-mix activities are systematically related to changes in SCR levels. 


\section{Acknowledgments}

The authors thank Information Resources, Inc. for its generous support of this project.

\section{Notes}

1. For example, the NPD Group refers to this measure as "Share of Requirements Satisfied."

2. Given the specific focus of our investigation, we shall not be reviewing the general brand loyalty literature. We recommend the interested reader to Jacoby and Chestnut (1978) for an excellent review.

3. For the ease of comparing the characteristics of the sample with those of the population, we present the actual (unstandardized) mean values of the different variables in Table 2. However, given that our data spans across 120 different product categories, we use standardized values for model estimation.

\section{References}

Allenby, Greg M., and Peter E. Rossi. (1991). "Quality Perceptions and Asymmetric Switching Between Brands." Marketing Science 10 (Summer), 185-204.

Blattberg, Robert C., and Kenneth J. Wisniewski. (1989). "Price Induced Patterns of Competition." Marketing Science 8 (Fall), 291-309.

Davis, Scott, J. Jeffrey Inman, and Leigh McAlister. (1992). “ Promotion Has a Negative Effect on Brand Evaluation Or Does It? Additional Disconfirming Evidence." Journal of Marketing Research 29 (February), 143-148.

DeSarbo, Wayne S., and William L. Cron. (1988). "A Conditional Mixture Maximum Likelihood Methodology for Clusterwise Linear Regression." Journal of Classification 5, 249-289.

DeSarbo, Wayne S., and Michel Wedel. (1995). "A Review of Latent Structure Regression Methods." In Richard Bagozzi (ed.), Advanced Marketing Research. Blackwell: London.

Dodson, Joe A., Alice Tybout, and Brian Sternthal. (1978). "Impact of Deals and Deal Retraction of Brand Switching." Journal of Marketing Research 15 (Fcbruary), 72-81.

Ehrenberg, A.S.C., Kathy Hammond, and Gerald J. Goodhardt. (1994). "The After-Effects of Price-Related Consumer Promotions." Joumal of Advertising Research (July-August) 11-21.

Etgar, Michael, and Naresh K. Malhotra. (1981). "Determinants of Price Dependency: Personal and Percentual Factors." Journal of Consumer Research 8 (September), 17-22.

Fader, Peter S., and David C. Schmittlein. (1993). "Triple Jeopardy: Excess Behavioral Loyalty Experienced by High-Share Brands." Journal of Marketing Research 30 (November), 478-493.

Farley, John U. (1964). "Why Does Brand Loyalty Vary Over Products." Journal of Marketing Research 1 (November), 9-14.

Farris, Paul, James Olver, and Cornelis de Kluyver. (1989). "The Relationship Between Distribution and Market Share." Marketing Science 8 (Spring), 107-127.

Gabor, Andre, and Clive W.J. Granger. (1966). "Price as an Indicator of Quality: Report on an Enquiry." Economica 46 (February), 43-70.

Guadagni, Peter M., and John D.C. Little. (1983). "A Logit Model of Brand Choice Calibrated on Scanner Data." Marketing Science 2 (Summer), 203-238.

Hume, Scott. (1992). "Brand Loyalty Steady." Advertising Age, March 2, p. 19.

Information Resources, Inc. (1988). InfoScan Supermarket Review. Chicago: Information Resources, Inc.

Information Resources, Inc. (1988). The Marketing Factbook Annual Report, January-December 1988. Chicago: Information Resources.

Jacoby, Jacob, and Robert W. Chestnut. (1978). Brand Loyalty: Measurement and Management. New York: Wiley. Johnson, lod. (1984). "The Myth of Declining Brand Loyalty." Journal of Advertising Research 24 (FebruaryMarch), 9-17.

Johnson, Tod. (1991). "Seventeen Years of Brand Loyalty Trends: What Do They Tell Us." Paper presentated to the Promotion Marketing Association of Advertising, March. 
Kahn, Barbara E., and Therese A. Louie. (1990). "Effects of Retraction of Price Promotions on Brand Choice Behavior for Variety-Seeking and Last-Purchase-Loyal Consumers." Journal of Marketing Research 27 (August), 279-289.

Kalwani, Manohar U., Chi Kin Yim, Heikki J. Rinne, and Yoshi Sugita. (1990). "A Price Expectations Model of Customer Brand Choice." Journal of Marketing Research 27 (August), 251-262.

Krishna, Aradhna. (1991). "Effect of Dealing Patterns on Consumer Perceptions of Deal Frequency and Willingness to Pay." Journal of Marketing Research 28 (November), 441-451.

Krishnamurthi, Lakshman, and S.P. Raj. (1988). "A Model of Brand Choice and Purchase Quantity Price Sensitivities." Marketing Science 7 (Winter), 1-20.

Lattin, James M. (1990). "Measuring Preference from Scanner Panel Data: Filtering Out the Effects of Price and Promotion." Unpublished working paper, Graduate School of Business, Stanford University.

Lattin, James M., and Randolph E. Bucklin. (1989). "Reference Effects of Price and Promotion on Brand Choice Behavior." Journal of Marketing Research 26 (August), 299-310.

Little, John D.C., and Eric Anderson. (1994). "A Product Choice Model with Marketing, Filtering and Purchase Feedback." Unpublished working paper, MIT Sloan School of Management.

Monroe, Kent B. (1973). "Buyers' Subjective Perceptions of Price." Journal of Marketing Research 10 (February), 70-80.

Neslin, Scott A., and Robcrt W. Shocmaker. (1989). "An Alternative Explanation for Lowcr Repeat Rates After Promotion Purchases." Journal of Marketing Research 26 (May), 205-213.

Ortmeyer, Gwen, James M. Lattin, and David B. Montgomery. (1991). "Individual Differences in Response to Consumer Promotions." International Journal of Research in Marketing, 8 (September), 169-186.

Ramaswamy, Venkataram, Wayne S. DeSarbo, David J. Reibstein, and William T. Robinson. (1993). "An Empirical Pooling Approach for Estimating Marketing Mix Elasticities with PIMS Data." Marketing Science 12 (Winter), 103-124.

Russell, Gary J. (1994). "Averaging Over the Past: When Simple Loyalty Measures Work." Paper presented at the Marketing Science Conference, University of Arizona.

Russell, Gary J., and Wagner A. Kamakura. (1994). "Understanding Brand Competition Using Micro and Macro Scanner Data." Journal of Marketing Research 31 (May), 289-303.

Srinivasan, V., and Thomas Kibarian. (1989). "Purchase Event Feedback: Fact or Fiction?" Paper presented at the Marketing Science Conference, Fuqua School of Business, Duke University.

Winer, Russell S. (1986). "A Reference Price Model of Brand Choice for Frequently Purchased Products." Journal of Consumer Research 13 (September), 250-256. 